\title{
Bioenergetics Race: Teaching Cellular Metabolism to High School Students Through an Educational Game
}

\author{
Silva, I.E.P. ${ }^{1}$; Azevedo, L.S. ${ }^{1}$; Souza, M.S. ${ }^{1}$; Silva, J.R. ${ }^{2}$; Pompilho, W.M. ${ }^{1}$ \\ ${ }^{1}$ CEDERJ, UENF, Itaperuna, RJ, Brazil; '²IBHM-NUPEM, UFRJ, Macaé, RJ.
}

Biochemistry is a science that deals with complex and abstract topics, which are often not understood by high school students, thus interfering in the teaching/learning process. The educational teaching game is a methodology advocated by several educators. The aim of this study was to develop a pedagogical practice to assist in the teaching/learning of high school students. In this context we designed a game about Metabolism, which was named "Bioenergetics Race". The game is simple, uses low cost materials and have easy access. The game consists of a board, chips, and a list with 100 multiple questions. Operation of the game: Selected questions lead the students to draw a card and move the corresponding number of squares on the board. The one who reaches the finish line first is the winner. To consolidate the proposal information, every answer was discussed. At the end of the game the students answered a questionnaire. According to $77.5 \%$ of players the level of difficulty was large and $83 \%$ rated the game as good for educational proposal. It was found that $100 \%$ of students had never participated in such activity in the classroom. It is notable the interest of students and the abstract and complex topics are better assimilated.

Keywords: Teaching of Biochemistry, High School, Cellular Metabolism. 
This document was created with Win2PDF available at http://www.win2pdf.com. The unregistered version of Win2PDF is for evaluation or non-commercial use only. This page will not be added after purchasing Win2PDF. 